\title{
Efficiency and Fairness in Revenue Sharing Contracts
}

\author{
By Alexandros Karakostas* Axel Sonntag ** and \\ Daniel John Zizzo**
}

* Faculty of Economics, Finance and Accounting, Coventry University

** Centre for Behavioural and Experimental Social Science (CBESS) and School of Economics, University of East Anglia

\begin{abstract}
If principals are allowed to choose between a revenue sharing, a bonus and a trust contract, a large majority of experimental subjects choose the revenue sharing contract. We find that this choice is the most efficient while at the same time being fair in the Paretian sense that on average agents are not worse off than in the other contracts. Furthermore, the distribution of earnings is only mildly skewed towards the principal. We conclude that under revenue sharing contracts concerns for fairness can go in hand with the use of monetary incentives.

\section{JEL classification codes}

C91, J41, M52

Keywords

efficiency, fairness, revenue sharing contract, bonus contract, trust contract, moral hazard
\end{abstract}
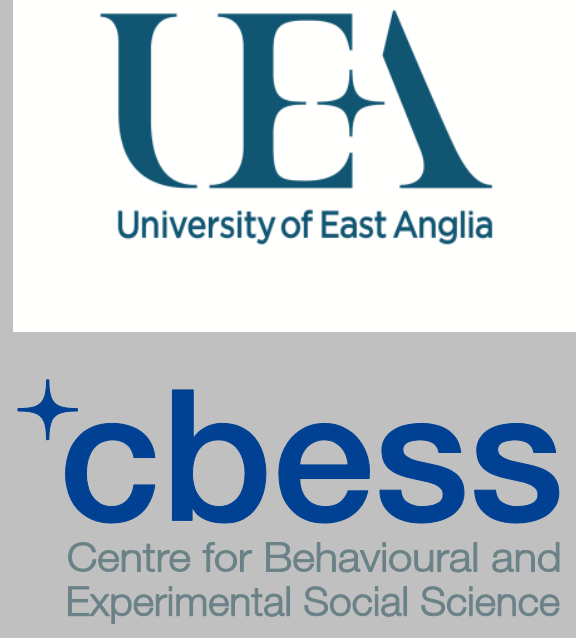

Centre for Behavioural and
Experimental Social Science

Centre for Behavioural and Experimental Social Science University of East Anglia Norwich Research Park Norwich NR4 7TJ United Kingdom www.uea.ac.uk/ssf/cbess 


\title{
Efficiency and Fairness in Revenue Sharing Contracts
}

\author{
Alexandros Karakostas ${ }^{1}$, Axel Sonntag ${ }^{2}$, Daniel John Zizzo ${ }^{3}$
}

April 2013

\begin{abstract}
If principals are allowed to choose between a revenue sharing, a bonus and a trust contract, a large majority of experimental subjects choose the revenue sharing contract. We find that this choice is the most efficient while at the same time being fair in the Paretian sense that on average agents are not worse off than in the other contracts. Furthermore, the distribution of earnings is only mildly skewed towards the principal. We conclude that under revenue sharing contracts concerns for fairness can go in hand with the use of monetary incentives.
\end{abstract}

Keywords: efficiency, fairness, revenue sharing contract, bonus contract, trust contract, moral hazard

JEL Classification: C91, J41, M52

1 Faculty of Economics, Finance and Accounting, Coventry University, Coventry, UK, e-mail: ab2992@coventry.ac.uk

2 Centre for Behavioural and Experimental Social Science (CBESS) and School of Economics, University of East Anglia, Norwich, UK, e-mail: a.sonntag@uea.ac.uk

${ }^{3}$ Centre for Behavioural and Experimental Social Science (CBESS) and School of Economics, University of East Anglia, Norwich, UK, e-mail: d.zizzo@uea.ac.uk. We thank Enrique Fatas, David Masclet, Anders Poulsen and participants to presentations in Norwich for encouragement and advice. The experimental instructions and other appendices can be found online. The experiment was programmed using ZTree (Fischbacher, 2007) and the experimental dataset is available from the first author. 


\section{Introduction}

This paper employs an experiment to explore how efficiency and fairness can complement each other in principal-agent relationships. Most of the work in principal-agent theory has focused on how to design contracts which incentivise agents financially to act according to their principals' expectations. ${ }^{4}$ That said, it has been noted that the use of monetary incentives may undermine intrinsic motivation (Gneezy \& Rustichini, 2000) or could have adverse effects in the long run (Benabou \& Tirole, 2003). Fehr et al. (2007) showed that, when offered the choice between an enforceable monitoring contract and a nonenforceable bonus contract, most principals (roughly 90\%) preferred the bonus contract. Their interpretation is that the bonus contract was preferred to the monitoring contract due to fairness concerns, and the effort exerted by the agents and the average payoff for both the principals and the agents were higher in bonus contract than in monitoring contract settings. It is possible however that a contract that contained the opportunity of fining could have been perceived as a hostile act itself and might send the agent a signal of distrust. This in turn could have increased the likelihood to shirk by generating a self-fulfilling prophecy of distrust (see Bacharach et al. 2007). In contrast, in an experiment employing only revenue sharing contracts, Anderhub et al. (2002) found that principals "clearly recognize the agency problem and react accordingly" (Anderhub et al. 2002, p.24) by developing incentive compatible and profit maximizing contracts; however, a significant proportion of the principals also take concerns of fairness into account in the sense of providing larger than the predicted shares of the total revenue to the agents.

Our experiment builds on Anderhub et al.'s (2002) important intuition to see how revenue sharing contracts fare where principals are given a choice among revenue sharing, Fehr et al.'s (2007) bonus contracts, and trust contracts as a third option. ${ }^{5}$ In our revenue sharing contract a principal defines a non-negative fixed wage and additionally offers the agent a share of the total (gross) revenue. The revenue sharing contract allows fairness concerns to be expressed by offering a generous share of the total revenue to the agent. Hence, a principal can express social preferences in both the bonus contract and the revenue sharing contract if she chooses to do so. We find support for Anderhub et al.'s (2002) intuition in the following sense: principals tend to choose revenue sharing contracts over alternatives, and the revenue sharing contracts that they choose make agents on average no worse off in absolute terms than if a different contract had been chosen. In relative terms, agents overall received as much as $47 \%$ of the earnings. Put differently, on average revenue sharing contracts are Pareto superior in absolute terms and with only a mild degree of

\footnotetext{
${ }^{4}$ For a review of the theoretical work in principal agent theory see Laffont and Martimort (2002).

5 As discussed greater below, the trust contract may be seen as a special case of both the bonus and the revenue sharing contracts. However, we chose to present it as an explicit option to control for any potential pressure the principals may have felt on using all the mechanisms available in each contract (given they have chosen it).
} 
inequality in relative terms. There is a sense therefore in which efficiency and fairness can complement each other. ${ }^{6}$

Our results are, in spirit, connected to Chan (2006), who presented a trust game experiment showing that both efficiency and equity can matter, and to Güth et al. (1993), who devised a multi-period ultimatum game where preferences for efficiency and for fairness can complement each other. Undoubtedly there are contexts where the tension rather than complementarity between efficiency and fairness is a real one (e.g. Ackert et al., 2007, and Bone et al., 2004), and one that is not easy to solve. In bargaining contexts such as ultimatum games or free-form bargaining games the threat point of the inefficient outcome can be avoided as long as some mutually minimum acceptable proposal is made. ${ }^{7}$ Our claim of complementarity is one that applies to a contract design environment where revenue sharing is a possible contract.

A different way of stating our results is that it finds some support for a utilitarian perspective on fairness (e.g., Favarelli, 2007; Konow, 2003; Lissowsky et al., 1991; Frohlich et al., 1987a, 1998b) in the way that revenue sharing contracts are chosen and yield higher aggregate social welfare (as one party is better off and the other is not worse off in absolute terms). ${ }^{8}$ Our results are in this sense also congruent with Charness and Rabin's (2002) conclusion regarding the motivational importance of raising social welfare together with other fairness concerns. That said, it is interesting that, even taking an alternative view of fairness in terms of purely of closeness to equal earnings, under revenue sharing we get fairly close to this equality ideal. ${ }^{9}$

The remainder of this article is structured as follows: Section 2 presents the theoretical predictions. The experimental design and hypotheses are stated in section 3 . Section 4 presents and discusses the results of the experiment before section 5 concludes. The experimental instructions as well as proofs for the theoretical prediction are provided in the appendix.

\section{The Principal Agent Problem and Contract Design}

A principal hires an agent to carry out production. The total revenue depends on the agent's effort level $e$ such that $R(e)=150 * e$. For providing effort, the agent bears a cost of $C(e)=e+e^{2}$ with $e \in\{0,1, \ldots, 19,20\}$.

\footnotetext{
${ }^{6}$ While following a different approach, there is some parallelism with Murdock (2002), who presents a model combining intrinsic incentives and efficiency in contract design. Conversely, Prendergast (2008) suggests selecting agents by their preferences and other researchers have pointed out that monetary incentives might work, but their effectiveness depends on the degree of the agents' intrinsic motivation (Boly, 2010) or the size of the monetary incentives (James, 2005).

7 Context may also affect what subjects may see as fair (Favarelli, 2007).

${ }^{8}$ Our work is less related to important papers such as Cappellen et al. (2011a, 2011b) and Gächter and Riedl $(2005,2006)$ as these provide insights into pure distribution problems.

${ }^{9} \mathrm{We}$ will refer to the revenue sharing contract as incentive contract or IC in this paper.
} 


\section{Trust contract (TC):}

In a trust contract the principal offers the agent an unconditional fixed wage $F$ and suggests the agent to provide an effort level $e^{s}$. However, if the agent accepts this offer, the suggested effort level $e^{s}$ cannot be enforced by the principal. Consequently, the principal's monetary payoff resulting from a trust contract $T C\left(F, e^{s}\right)$ is defined as $\mathrm{R}(\mathrm{e})-\mathrm{F}$, whereas the agent earns $\mathrm{F}-\mathrm{C}(\mathrm{e})$.

\section{Bonus contract $(B C)$ :}

Similarly to the trust contract, the principal offers a fixed wage $F$ and suggests an effort level $e^{s}$. However, differently from the TC, the principal also announces to pay a bonus $B \in\{0,1, \ldots, 2999,3000\}$ if the agent delivers the suggested effort level. After the agent's effort choice, the principal has the opportunity to pay the agent a voluntary bonus in addition to the fixed wage $F$. Neither the agent's effort level $e$ nor the principal's bonus payment $B$ are enforceable.

\section{Incentive contract (IC):}

The principal decides on a fixed wage $F$ and a share $S \in\{0.00,0.01, \ldots, 0.99,1.00\}$ that specifies how much of the totally generated revenue is returned to the agent. In contrast to the bonus payment $B$, the amount $R(e) * S$ is compulsory part of the incentive contract, i.e. there is no uncertainty involved whether the principal might pay a bonus and - if at all - what amount, but the agent by choosing his effort level also determines her or his own income. The agent's payoff in our incentive contract setting is $\mathrm{F}+\mathrm{S} * \mathrm{R}(\mathrm{e})-\mathrm{C}(\mathrm{e})$. Conversely, the principal's payoff is $\mathrm{R}(\mathrm{e}) *(1-\mathrm{S})-\mathrm{F}$. The expected payoffs for principals and agents are on top of their initial endowment.

$$
\begin{aligned}
& P^{P}=\left\{\begin{array}{lr}
R(e)-F & \text { for TC } \\
R(e)-F-B & \text { for } B C \\
R(e) *(1-S)-F & \text { for IC }
\end{array}\right. \\
& P^{A}=\left\{\begin{array}{lr}
F-C(e) & \text { for TC } \\
F+B-C(e) & \text { for BC } \\
F+S * R(e)-C(e) & \text { for IC }
\end{array}\right.
\end{aligned}
$$

Under the assumption that both, principals and agents behave as selfish payoff maximizers, principals should never choose the trust contract or the bonus contract. In both contracts, TC and BC, a selfish agent has no incentive to provide a higher effort level than zero. As the principal anticipates this, she should never offer such a contract with a fixed wage greater than zero. The incentive contract, however, due to the compulsory structure of $R(e) * S$, potentially provides sufficient monetary incentives to achieve a Pareto improvement. An online appendix shows that, given our experimental parameters, selfishly payoff maximizing principals should choose the incentive contract, suggest an effort level of 20 and offer a revenue share of 0.27 , which is the lowest share to incentivize the desired level of effort from agents. 


\section{Experimental Design and Hypotheses}

\subsection{Experimental Design}

Subjects had a fixed role of either principals or agents, and this was common knowledge. The experiment was divided in 5 games and had 10 rounds in total. In each game principals were matched with a different agent, and this absolute stranger between-games feature of the experiment was again common knowledge. Games were in one of two possible orders, described in Figure 1, and are described below.

[insert Figure 1 about here]

The exogenous Trust Contract game (ex.TC)

Subjects are in a trust contract (TC) setting. (1) The principal chooses the size of the fixed wage and suggests an effort level to the agent. (2) The agent is then informed about the offered contract and decides on an effort level. (3) Finally, both the agent and the principal get informed about their earnings.

\section{The exogenous Bonus Contact game (ex.BC)}

Subjects are in a bonus contract (BC) setting. (1) The principal chooses the fixed wage and suggests an effort level to the agent; in addition, he or she chooses the size of the bonus he or she will offer if satisfied by the effort level by the agent. (2) The agent is then informed about the offered contract and decides on an effort level. (3) After being informed about the agent's effort level, the principal chooses the bonus he or she wants to give to the agent, if any. (4) Finally, both the agent and the principal get informed about their earnings.

\section{The exogenous Incentive Contract game (ex.IC)}

Subjects are in an incentive contract (IC) setting. (1) The principal chooses the fixed wage, the share of the total revenue that will be given to the agent; he or she also suggests an effort level. (2) The agent is then informed about the offered contract and decides on an effort level. (3) Finally, both the agent and the principal get informed about their earnings.

\section{The one shot Trust-Bonus-Incentive game (TBI)}

The game sequence is as follows: (1) The principal chooses which of the 3 possible contracts to offer; (2) the principal chooses the values for the parameters of the chosen contract and suggests an effort level to the agent; (3) the agent is then informed about the offered contract and decides on an effort level; (4) if and only if the bonus contract has been chosen, after being informed about the agent's effort level, the principal chooses the bonus he or she wants to give to the agent, if any; (5) finally, both the agent and the principal get informed about their earnings.

The repeated Trust-Bonus-Incentive (TBI-r) games

This game is identical to the TBI but is repeated for 6 rounds with the same co-player.

Experimental Sequence 
Subjects read the instructions and filled a short questionnaire for the purpose of checking their understanding; explanations of any incorrect answer were provided by the software. Then three practice games, identical to the ex.TC, ex.BC, and ex.IC games, were played to help the subjects familiarize with the experiment (the co-player was the computer and chose randomly, and subjects knew this). The participants could ask questions at the end of each practice round.

The ten payoff-relevant rounds were then played, consisting of one round of ex.TC, ex.BC, ex.IC, and TBI each, plus a TBI-r game of six rounds. The order of games was counterbalanced as indicated in Figure 1. At the end of the experiment each participant was paid anonymously and discretely. A random lottery payment mechanism was used, i.e. one of the ten payoff-relevant rounds was randomly chosen and the participants were paid according to their performance in the randomly selected round. The Experimental Currency Units (ECUs) earned in the randomly selected round were converted into pounds at the rate of $£ 0.004$ per ECU. Subjects earned $£ 15.46$ on average for about 1 hour and 30 minutes of work.

\subsection{Hypotheses}

We state our hypotheses under the rational self-interest benchmark. Under this assumption, in the one shot bonus or trust contracts a zero fixed wage, zero effort and (in the case of the bonus contract) a zero bonus is given. Conversely, by choosing a suitable revenue share for the agent, the agent puts in more effort and both principal and agent earn more profits. Assuming that this result is robust to eventual supergame (reputational) effects in the TBI-r, it is expected that:

H1 Principals prefer the incentive contract over the bonus or trust contract.

H2 Agents provide more effort in incentive contracts than in bonus contract or trust contracts.

H3 Total revenue is higher in incentive contracts than in bonus or trust contracts.

As mentioned above and derived in the online appendix, there is a point prediction for the amount that principals will offer in the incentive contract:

H4 In incentive contracts, principals offer incentive compatible contracts, and specifically the lowest feasible incentive compatible share of 0.27 .

Under rational self-interest we should have a 60:40 split of the profits in favor of the principal (see online appendix); a distribution clearly different from an equal split. However, it is possible that distributional fairness may come into play, and if so we might be finding a more equal distribution than the profit maximizing prediction.

H5 In incentive contracts, the overall profits are distributed in a ratio of 60:40 between principals and agents to the disadvantage of the latter. 


\section{Results}

A total of 144 subjects participated in the experiment which was conducted at the CBESS laboratory at the University of East Anglia. Table 1 presents key descriptive statistics about the experiment. In a regression analysis (reproduced in an online appendix), we show that, as we would expect, in the bonus contract the actually paid bonus was a positive function of revealed effort; specifically, one each extra unit of effort led to around $35 \mathrm{ECU}$ in extra bonus $(\mathrm{p}<0.001){ }^{10}$

\section{[Insert Table 1 about here.]}

Result 1. H1 is supported. When given the option to choose between the three contracts, both in the one shot (TBI) and the repeated games (TBI-r) three choices out of four were in favor of the incentive contract IC.

\section{[Insert Figures 2 and 3 about here.]}

Support. The incentive contract was chosen $75 \%$ of the times, against $21 \%$ and $4 \%$ of choices for the bonus contract and the trust contract, respectively (see Figure 2); these differences are all significant in Wilcoxon tests (TC<->IC: $\mathrm{p}<0.001$ for TBI and TBI-r, BC $<-$ $>$ IC: $\mathrm{p}<0.001$ for TBI and TBI-r; TC<->BC: $\mathrm{p}=0.007$ for TBI and $\mathrm{p}<0.001$ for TBI-r). ${ }^{11}$ Figure 2 shows that the distribution of choices is virtually indistinguishable between TBI and TBI-r $\left(\chi^{2}\right.$-test $\left.p>0.1\right)$. Figure 3 provides complementary evidence in favor of $\mathrm{H} 1$ by showing an upward trend in choice of the Incentive contract in the TBI-r, from $71 \%$ in the first round to $86 \%$ in the last one. ${ }^{12}$

Result 2. H2 is supported. Effort was highest in incentive contracts relative to trust contracts and bonus contracts.

\section{[Insert Figure 4 and Table 2 about here.]}

Support. Tables 1 and 2, and Figure 4, support this result. The levels of actually revealed effort by the agents in incentive contract situations were significantly higher for bonus or trust contract settings. This is true for the overall sample and for each of the games separately $(p<0.05)$. Further, the bonus contract was significantly better than the trust contract. ${ }^{13}$ Considering the regression results, the coefficient on the IC dummy is significant $(\mathrm{p}<0.001)$, implying an increase in effort in incentive contracts by more than 7 points relative

\footnotetext{
10 The online appendix includes a hierarchical linear regression model with error clustering by subjects and sessions, in which no other variable is statistically significant.

11 In this paper, all non-parametric test statistics were calculated on session level means per game (ex.TC, ex.BC, ex.IC, TBI, or TBI-r), unless stated otherwise. All $\mathrm{p}$ values in the paper are two tailed unless otherwise specified.

12 A multilevel probit regression with subjects nested in sessions on the likelihood of choosing the Incentive contract shows a statistically significant positive time trend $(\mathrm{p}<0.001)$.

13 This is true for the overall sample, the exogenously set games and TBI-r $(p<0.05)$. In TBI the difference between bonus and trust contracts was not statistically significant due to the very small number of observations of TC $(\mathrm{p}=0.26)$.
} 
to the trust contract, and is also statistically significantly higher than the (non-significant) one on the BC contract $(\mathrm{p}=0.989)$. Moreover, all the results in Table 2 imply that suggested effort positively affected actual effort. ${ }^{14}$ Other contract details mattered: in the BC, effort increased in the size of the announced bonus $(\mathrm{p}<0.001)$ and, in the IC, it increased with the revenue share offered to the agent $(\mathrm{p}<0.01)$, particularly if incentive incompatible, i.e. the offered share was equal to or higher than 0.27 ( $p<0.01)$. Overall, increasing the fixed wage significantly increased effort $(\mathrm{p}<0.05)$. However, this result is mainly driven by the trust contracts. Whereas the interaction of $\mathrm{BC}$ and fixed wage is not significant anyway, the interaction of IC and fixed wage has a significant negative coefficient, resulting in a negative cumulative effect for IC. ${ }^{15}$

Result 3. H3 is supported. The incentive contract was the most efficient contract in terms of total revenue.

\section{[Insert Table 3 about here.]}

Support. Table 3 reports the average total revenue generated within each chosen contract type. On average, the incentive contract IC generated approximately $66 \%$ more total revenue than the bonus contract, with $68 \%$ more total revenue than $\mathrm{BC}$ in TBI and $45 \%$ in TBI-r. The trust contract was the worst alternative with respect to efficiency. Wilcoxon tests confirm that the average total revenue in IC-ex is higher than in BC-ex $(p<0.001)$ and TC-ex $(\mathrm{p}<0.001)$ and that similarly, when there is a choice of contracts, as in TBI and TBI-r, the incentive contract outperforms the bonus contract $(p=0.003)$ and the trust contract $(p<0.001)$ in terms of revenue. ${ }^{16}$

Result 4. As predicted by $\mathrm{H} 4$, over $70 \%$ of offered incentive contracts were incentive compatible. However, offers tend to be higher than lowest incentive compatible share of 0.27 . This cannot be explained by rejections of offers above 0.27 , as the rejection rate was almost the same for offers below or above 0.27 .

\section{[insert Table 4 and Figure 5 about here]}

Support. Table 4 shows that over $70 \%$ of offered incentive contracts were incentive compatible. However, not a single principal chose a revenue share of exactly 0.27 , the share predicted by H4. ${ }^{17}$ The mean offered share was 0.382 (median 0.4 ), and was not significantly different across ex.IC, TBI, and TBI-r games. ${ }^{18}$ Further, the actually offered shares were

\footnotetext{
14 Unlike actual effort, suggested effort did not change across treatments, and tended to be close to the maximum of 20 (see Table 1).

${ }^{15}$ This finding is consistent with the descriptive results in Table 1 which indicate that the fixed wage is lower for incentive contracts than for bonus or trust contracts.

16 Average total revenue was not significantly different between TBI and TBI-r rounds (for all contract types, $\mathrm{p}>0.4)$.

17 This is true for all IC occurrences irrespective the game type (IC-ex, TBI, and TBI-r). However, over 60\% of the incentive contracts offered "round shares", i.e. shares that had either 0 or 5 at the second decimal place.

${ }^{18}$ All tests reveal $\mathrm{p}>0.4$.
} 
significantly higher than the lowest incentive compatible share of 0.27 (sign test $\mathrm{p}<0.001){ }^{19}$ Figure 5 shows the frequencies of incentive contract offers and whether offers were accepted or rejected by the agents. Overall, about $7 \%$ of the incentive contracts were rejected. When the offered share was greater than or equal to 0.27 only $6 \%$ of the contracts were rejected whereas $11 \%$ of offers with shares of less than 0.27 were rejected. Comparing three areas of offered shares, i.e. $S<0.27,0.27 \leqslant S<0.5$, and $S \geqslant 0.5$, we found no statistical difference regarding the rate of rejections between the contract offers with $S<0.27$ and $0.27 \leqslant S<0.5$ (Wilcoxon $\mathrm{p}=0.501$ ). However, the rejection rates of contracts that offered $\mathrm{S} \geqslant 0.5$ were significantly lower than for offers of either $S<0.27$ or $0.27 \leqslant S<0.5$ (Wilcoxon $p=0.057$ and $\mathrm{p}=0.001$, respectively). ${ }^{20}$

As raising the revenue share over 0.27 cannot be explained by selfish profit maximization, it is consistent with the findings of Anderhub et al. (2002), which suggest concerns for fairness to be the influential factor behind offers higher than the incentive compatibility constraint. An alternative interpretation would be that offering larger shares increases the salience of the opportunity to benefit from contributing high effort levels.

Result 5. Against H5, incentive contracts were fairer than the profit maximizing prediction and close to a 50-50\% split.

\section{[insert Table 5 about here]}

Support. Because of most incentive contracts having a revenue share for the agent of more than 0.27 , as shown in Result 4, we would expect to observe a split that is more equal than $60-40 \%$ for the principal. Table 5 shows that this is indeed the case, with $53 \%$ going to the principal in the exogenous incentive contract (IC-ex), 53\% in the one-shot game selected incentive contracts (TBI) and 54\% in the repeated game selected incentive contracts (TBI-r), percentages all significantly lower than $60 \%$ (Wilcoxon $\mathrm{p}<0.001$ ). ${ }^{21}$ Comparing our profit distribution with empirical findings from other games suggests that that a 53:47 or 54: 46 split is quite close to an equal split (Fehr \& Schmidt 1999; Güth et al. 1982).

Result 6. Incentive contracts on average were more efficient than bonus or trust contracts: they led to a significantly higher total surplus than bonus or trust contracts. Welfare gains were mostly absorbed by the principals.

\section{[Insert Table 6 about here]}

Support. Table 6 shows that the overall profits were higher in incentive contracts than in trust contracts (Wilcoxon $\mathrm{p}<0.001, \mathrm{p}=0.011, \mathrm{p}<0.001$ in relation to exogenous contracts, TBI and TBI-r respectively) and bonus contracts (Wilcoxon $\mathrm{p}<0.001, \mathrm{p}=0.05$, $\mathrm{p}<0.001$ in relation to exogenous contracts, TBI and TBI-r respectively).

\footnotetext{
${ }^{19}$ This is not only true for the full sample but also holds for each game separately $(\mathrm{p}<0.05)$.

${ }^{20}$ The average rejection rates were $9 \%$ and $1 \%$ for $0.27 \leq \mathrm{S}<0.5$ and $\mathrm{S} \geq 0.5$, respectively.

${ }^{21}$ We find no significant difference between IC-ex, TBI, and TBI-r rounds ( $\left.p>0.2\right)$.
} 
Table 6 also shows that the principals largely absorbed the surplus, earning more in incentive contracts than in the other contracts (18\% more than with bonus contracts and $44 \%$ more than with trust contracts). ${ }^{22}$ This higher efficiency applies across all games, and therefore explains why, when a choice was given, principals tended to choose incentive contracts (as shown in Figure 3 above).

The agents average profit were larger when an IC was implemented when compared to a BC (Wilcoxon $\mathrm{p}=0.039$ ), and at least the same under TC (Wilcoxon $\mathrm{p}=0.089$ ). ${ }^{23}$ The share of the surpluses between principals and agents was almost the same under all three contract types, being very close to the equal split. Agents were almost no worse off in incentive contracts than they were in the other contracts (3\% relative to trust contracts and $4 \%$ relative to bonus contracts). ${ }^{24}$

\section{Conclusions}

This paper explored how monetary incentives and intrinsic motivation can complement each other in principal-agent settings. We combined Fehr et al.'s (2007) bonus contract with an adapted version of Anderhub et al.'s (2002) revenue sharing contract and added a trust contract as a third option. In contrast to Fehr et al. (2007) who found that only $10 \%$ of the principals chose the enforceable monetarily incentivized contract, in our experiment up to $86 \%$ of the principals chose such an option. They did so because they could earn a higher revenue as a result while obtaining a share of the pie close to $50-50 \%$ and ensuring that on average agents are at least as well off as if the other contracts had been chosen. ${ }^{28}$ In this sense, in our setting the choice of revenue sharing contract leads, on average and in terms of revenue, to a Pareto superior outcome - one where principals are better off while agents are not worse off in absolute terms (and only marginally so in relative terms). Because of this, we conclude that revenue contracts can combine efficiency and fairness. ${ }^{29}$

\footnotetext{
${ }^{22}$ With respect to trust contracts: Wilcoxon $\mathrm{p}<0.001, \mathrm{p}=0.011, \mathrm{p}<0.001$ in relation to exogenous contracts, TBI and TBI-r respectively. With respect to bonus contracts: Wilcoxon $\mathrm{p}=0.004, \mathrm{p}=0.028, \mathrm{p}<0.001$ in relation to exogenous contracts, TBI and TBI-r respectively.

23 These differences are maintained under the Exogenous contracts $\mathrm{BC}<->\mathrm{IC}: \mathrm{p}=0.005$ and TC<->IC: $\mathrm{p}=0.078$. But the results are not significant for TBI (BC<->IC: $\mathrm{p}=0.508 \mathrm{TC}<->\mathrm{IC}$ : $\mathrm{p}=0.036)$ and TBI-r $(\mathrm{BC}<->\mathrm{IC}$ : $\mathrm{p}=0.551$, TC<->IC: $\mathrm{p}=0.432$ ). In any case these results suggest that the agents were at least not worse off in terms of earnings when an IC was implemented.

${ }^{24}$ With respect to trust contracts: Wilcoxon $\mathrm{p}=0.078, \mathrm{p}=0.036, \mathrm{p}=0.432$ in relation to exogenous contracts, $\mathrm{TBI}$ and TBI-r respectively. With respect to bonus contracts: Wilcoxon $\mathrm{p}=0.005, \mathrm{p}=0.508, \mathrm{p}=0.551$ in relation to exogenous contracts, TBI and TBI-r respectively.

${ }^{28}$ Furthermore, we found that incentive contracts were systematically less risky than bonus contracts and not systematically more risky than trust contracts.

${ }^{29}$ Further research would of course be useful and could investigate, for example, if the results observed here can be replicated in a multitasking environment or how positively incentivized contracts would be affected by the introduction of risk.
} 


\section{References}

Ackert, L., Martinez-Vazquez, J. \& Rider, M., 2007, Social Preferences and Tax Policy Design: Some Experimental Evidence. Economic Inquiry 45(3), 487-501.

Anderhub, V., Gächter, S. \& Königstein, M., 2002. Efficient Contracting and Fair Play in a Simple Principal-Agent Experiment. Experimental Economics, 27(5), pp.5-27.

Bacharach, M., Guerra, G. \& Zizzo, D.J., 2007. The Self-Fulfilling Property of Trust: An Experimental Study. Theory and Decision, 63(4), pp.349-388.

Benabou, R. \& Tirole, J., 2003. Intrinsic and Extrinsic Motivation. Review of Economic Studies, 70(3), pp.489-520.

Boly, A., 2010. On the incentive effects of monitoring: evidence from the lab and the field. Experimental Economics, 14(2), pp.241-253.

Bone, J., Hey, J., \& Suckling, J., 2004, A Simple Risk-Sharing Experiment. Journal of Risk and Uncertainty 28(1), 23-38

Cappelen, A. W., A. D. Hole, E. Ø. Sørensen \& Tungodden, B., 2011. The Importance of Moral Reflection and Self-Reported Data in a Dictator Game with Production. Social Choice and Welfare 36(1), 105-120.

Cappelen, A. W., E. Ø. Sørensen \& Tungodden, B., 2011. Responsibility for What? Fairness and Individual Responsibility. European Economic Review 54(3), 429-441.

Chan, K.S., 2006. Trust Games, the Moral of the Story. Pacific Economic Review 11(2), 223-246.

Dickinson, D. \& Villeval, M.-C., 2008. Does monitoring decrease work effort? Games and Economic Behavior, 63(1), pp.56-76.

Favarelli, M., 2007. How Context Matter: A Survey Based Experiment on Distributive Justice. Journal of Public Economics 91(7-8), 1399-1422.

Fehr, E. \& Gächter, S., 2002. Do Incentive Contracts Undermine Voluntary Cooperation?, University of Zurich - Working Paper Series (34)

Fehr, E., Kirchsteiger, G. \& Riedl, A., 1998. Gift exchange and reciprocity in competitive experimental markets. European Economic Review, 2921(42), pp.1-34.

Fehr, E., Klein, A. \& Schmidt, K.M., 2007. Fairness and Contract Design. Econometrica, 75(1), pp.121-154.

Fehr, E. \& Schmidt, K.M., 1999. A Theory of Fairness, Competition, and Cooperation. The Quaterly Journal of Economics, 114(3), pp.817-868. 
Fehr, E. \& Schmidt, K.M., 2007. Adding a Stick to the Carrot? The Interaction of Bonuses and Fines. The American Economic Review, 97(2), pp.177-181.

Fehr, E. \& Schmidt, K.M., 2004. Fairness and Incentives in a Multi-Task PrincipalAgent Model. , University of Munich, Munich Discussion Paper No. 2004-8.

Frohlich, N., Oppenheimer, J., Eavy, C., 1987a. Choices of Principles of Distributive Justice in Experimental Groups. American Journal of Political Science 31(3), 606-636.

Frohlich, N., Oppenheimer, J., Eavy, C., 1987b. Laboratory Results on Rawls's Distributive Justice. British Journal of Political Science 17(1), 1-21.

Gächter, S. \& Riedl, A., 2005. Moral Property Rights in Bargaining with Infeasible Claims. Management Science 51(2), 249-263.

Gächter, S. \& Riedl, A., 2006. Dividing Justly in Bargaining Problems with Claims. Social Choice and Welfare 27(3), 571-594.

Gneezy, U. \& Rustichini, A., 2000. Pay Enough or Don't Pay at All. The Quarterly Journal of Economics, 115(3), pp.791-810.

Güth, W., Schmittberger, R. \& Schwarze, B., 1982. An experimental analysis of ultimatum bargaining. Journal of Economic Behavior and Organization, 3, pp.367-388.

James, H.S., 2005. Why did you do that? An economic examination of the effect of extrinsic compensation on intrinsic motivation and performance. Journal of Economic Psychology, 26(4), pp.549-566.

Konow, J., 2003. Which is the Fairest One of All? A Positive Analysis of Justice Theories. Journal of Economic Literature 41(4), 1188-1239.

Laffont, J. and Martimort, D. 2002. The theory of incentives: The principal-agent model. Princeton, NJ: Princeton University Press.

Lazear, E.P., 1986. Incentive Contracts. , National Bureau of Economic Research Working Paper Series (1917).

Murdock, K., 2002. Intrinsic Motivation and Optimal Incentive Contracts. RAND Journal of Economics, 33(4), pp.650-671.

Prendergast, C., 2008. Intrinsic Motivation and Incentives. American Economic Review, 98(2), pp.201-205. 
Figure 1: Sequential Structure of the Experiment

Sessions 1-6

\begin{tabular}{|c|c|c|c|c|}
\hline ound 1 & $\begin{array}{r}\mathrm{R} \\
\text { ound } 2-7\end{array}$ & ound $8^{\mathrm{R}}$ & ound 9 & $\begin{array}{r}\mathrm{R} \\
\text { ound } 10\end{array}$ \\
\hline $\begin{array}{l}\mathrm{T} \\
\mathrm{BI}\end{array}$ & BI-r & ${ }_{\text {C-ex }}{ }^{\mathrm{T}}$ & C-ex & C-ex \\
\hline
\end{tabular}

Sessions 7-12

\begin{tabular}{|c|c|c|c|c|}
\hline ound 1 & ound $2^{\mathrm{R}}$ & ound $3^{\text {R }}$ & ound $4^{\text {R }}$ & nd 5-10 \\
\hline $\begin{array}{ll} & \mathrm{T} \\
\mathrm{C}-\mathrm{ex} & \end{array}$ & $\begin{array}{ll} & \text { B } \\
\text { C-ex } & \end{array}$ & ${ }_{\text {C-ex }}$ & $\mathrm{T}$ & TBI \\
\hline
\end{tabular}

Notes: In the games ex.TC, ex.BC, and ex.IC the contracts could not be chosen but were set exogenously to be a Trust, Bonus, and Incentive Contract, respectively. TBI and TBI-r represent a one shot and repeated contract choice settings, respectively.

Figure 2: Percentages of chosen contracts in one shot (TBI) and repeated choice (TBI-r) settings

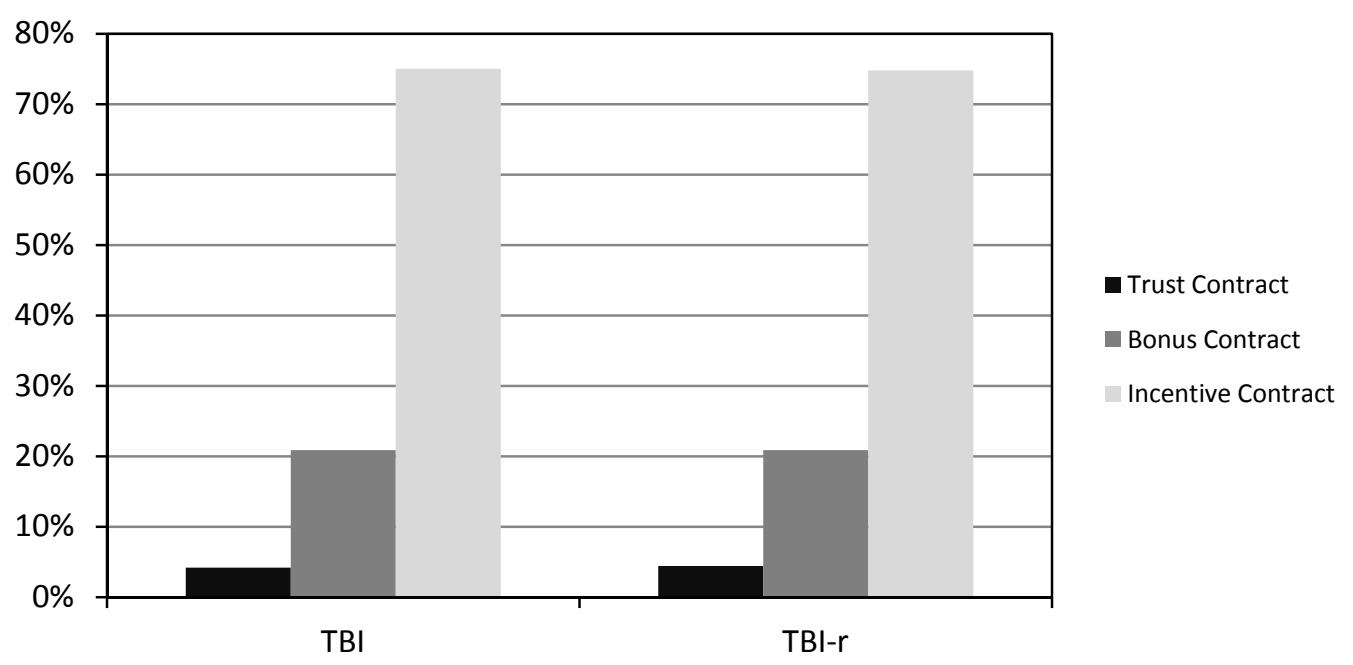


Figure 3: Percentage of chosen contracts over time in repeated contract choice settings (TBI-r)

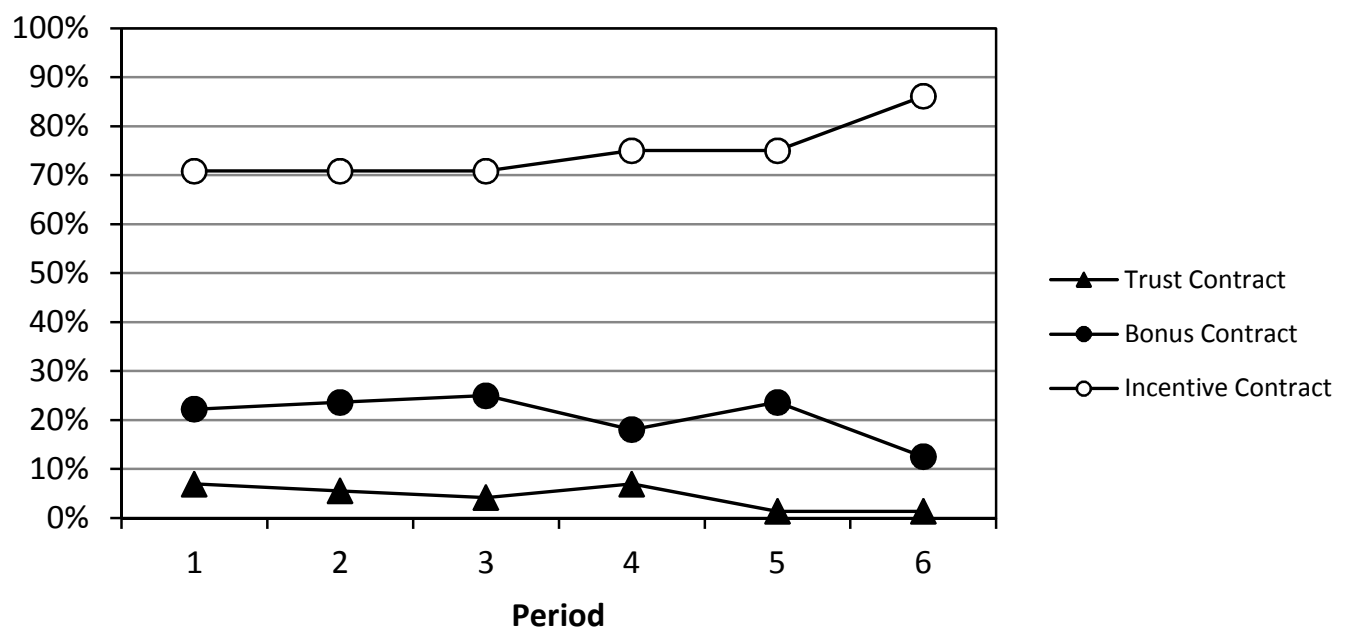

Figure 4: Revealed effort by contract type over time in repeated contract choice settings (TBI-r)

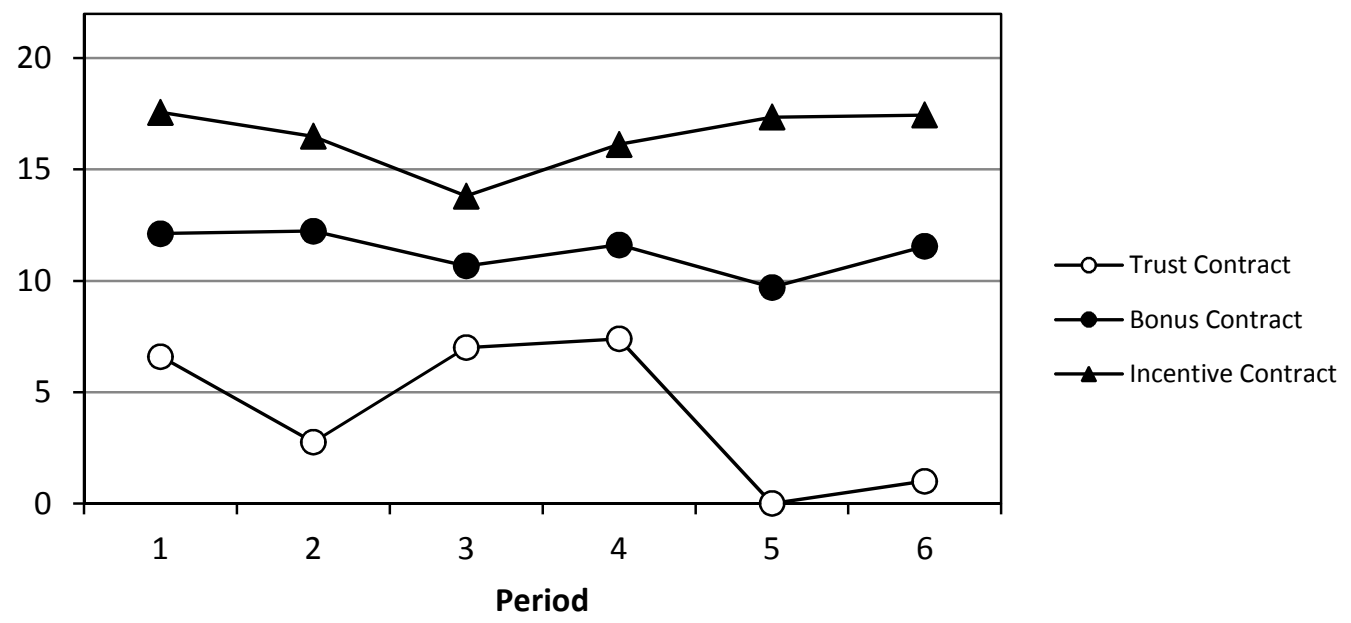


Figure 5: Histograms of revenue shares offered by principals

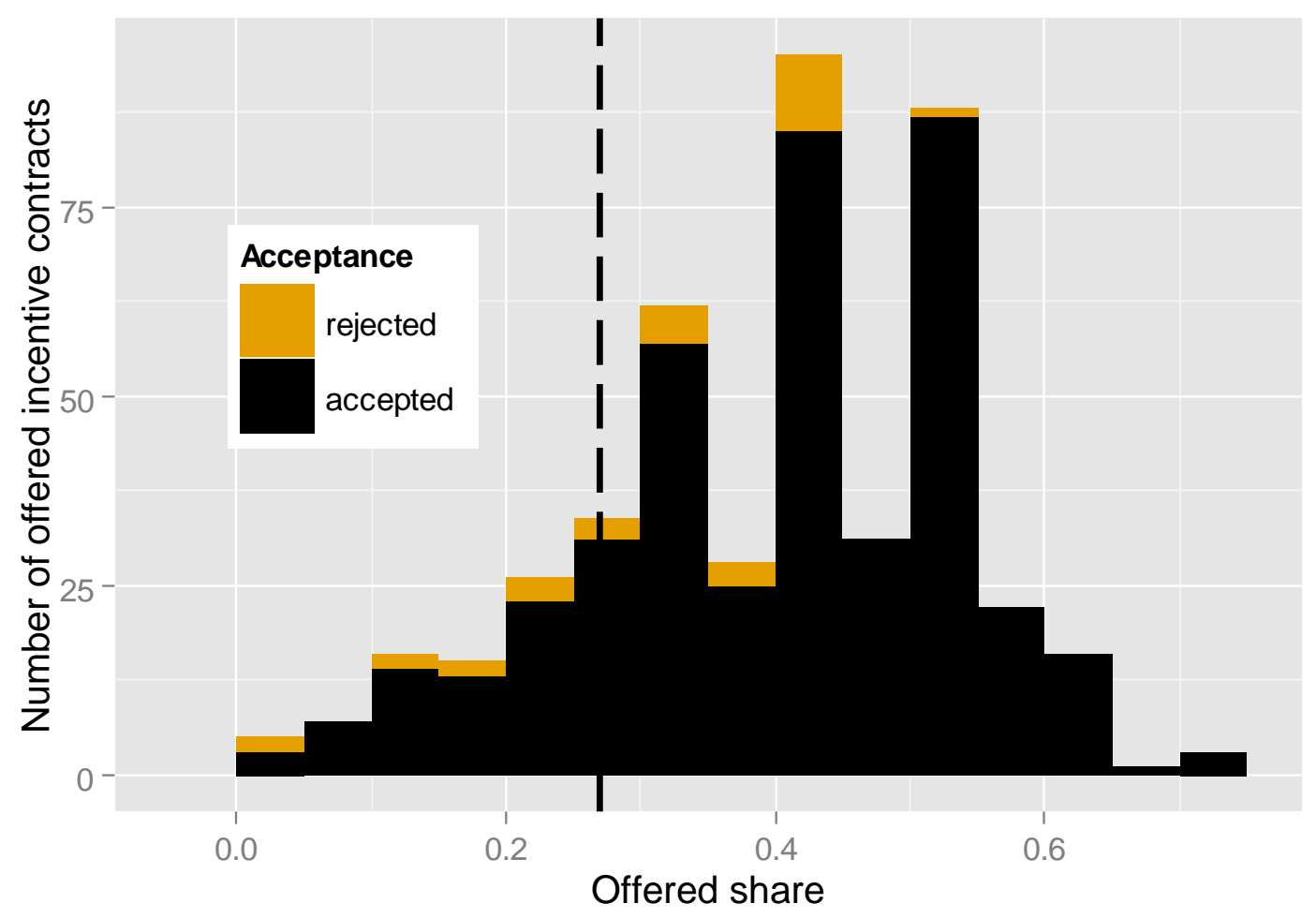

Note: This figure includes observations of all incentive contracts, irrespective the actual setting (IC-ex, TBI and TBI-r). 
Table 1: Descriptive Statistics of the Experiment

\begin{tabular}{|c|c|c|c|c|c|c|c|c|c|}
\hline & \multicolumn{3}{|c|}{ Exogenous contract } & \multicolumn{3}{|l|}{ TBI } & \multicolumn{3}{|c|}{ TBI-r: All Rounds } \\
\hline & TC-ex & BC-ex & IC-ex & $\mathrm{TC}$ & $\mathrm{BC}$ & IC & $\mathrm{TC}$ & $\mathrm{BC}$ & IC \\
\hline $\mathrm{n}$ & $\overline{72}$ & 2 & 2 & 3 & 5 & 4 & 9 & 0 & 323 \\
\hline Mean F & 95 & 04 & 188 & 500 & 791 & 15 & 952 & 573 & 125 \\
\hline Mean B & - & 151 & - & - & 127 & 0 & - & 420 & 0 \\
\hline Mean S & - & - & 0.354 & - & 0 & 0.395 & - & 0 & 0.378 \\
\hline Mean $\mathrm{e}^{\mathrm{s}}$ & 14.78 & 18.19 & 18.78 & 9.33 & 18.80 & 19.61 & 18.00 & 18.39 & 19.49 \\
\hline \multirow[t]{3}{*}{ Mean e } & 4.92 & 8.68 & 14.92 & 1.33 & 9.47 & 15.93 & 5.42 & 11.27 & 16.50 \\
\hline & \multicolumn{3}{|c|}{ TBI-r: Round 1} & \multicolumn{3}{|c|}{ TBI-r: Round 2} & \multicolumn{3}{|c|}{ TBI-r: Round 3} \\
\hline & $\mathrm{TC}$ & $\mathrm{BC}$ & IC & $\mathrm{TC}$ & $\mathrm{BC}$ & IC & $\mathrm{TC}$ & $\mathrm{BC}$ & IC \\
\hline $\mathrm{n}$ & 5 & 16 & 51 & 4 & 17 & 51 & 3 & 18 & 51 \\
\hline Mean F & 1520 & 698 & 105 & 900 & 584 & 160 & 475 & 673 & 171 \\
\hline Mean B & - & 576 & - & - & 595 & - & - & 416 & - \\
\hline Mean S & - & - & 0.375 & - & - & 0.361 & - & - & 0.358 \\
\hline Mean $\mathrm{e}^{\mathrm{s}}$ & 19.6 & 18 & 19.06 & 14 & 18.29 & 19.55 & 19.33 & 16.67 & 19.39 \\
\hline \multirow[t]{3}{*}{ Mean e } & 6.6 & 12.13 & 17.57 & 2.75 & 12.24 & 16.49 & 7 & 10.67 & 13.8 \\
\hline & \multicolumn{3}{|c|}{ TBI-r: Round 4} & \multicolumn{3}{|c|}{ TBI-r: Round 5} & \multicolumn{3}{|c|}{ TBI-r: Round 6} \\
\hline & $\mathrm{TC}$ & $\mathrm{BC}$ & IC & $\mathrm{TC}$ & $\mathrm{BC}$ & IC & $\mathrm{TC}$ & $\mathrm{BC}$ & IC \\
\hline $\mathrm{n}$ & 5 & 13 & 54 & 1 & 17 & 4 & 1 & 9 & 2 \\
\hline Mean F & 1014 & 544 & 152 & 200 & 465 & 98 & 200 & 374 & 76 \\
\hline Mean B & - & 423 & - & - & 312 & - & - & 23 & - \\
\hline Mean S & - & - & 0.366 & - & - & 0.394 & - & - & 0.405 \\
\hline Mean $\mathrm{e}^{\mathrm{s}}$ & 19.2 & 19.54 & 19.56 & 19 & 19.41 & 19.74 & 15 & 19.11 & 19.61 \\
\hline Mean e & 7.4 & 11.62 & 16.13 & 0 & 9.71 & 17.35 & 1 & 11.56 & 17.45 \\
\hline
\end{tabular}

Notes: n: number of choices ( 1 for each subject in TC-ex, BC-ex, IC-ex; or dependent on contract choice by the principal in the TBI and TBI-r); F: fixed wage; B: bonus in the BC only; S: share of revenue to go to agent in IC; es: suggested effort; e: effort. 
Table 2: Determinants of Agents' Effort for Accepted Contracts

\begin{tabular}{|c|c|c|c|c|c|c|}
\hline & \multicolumn{2}{|c|}{$\begin{array}{l}\text { Hierarchical linear model } \\
\text { (subjects in sessions) }\end{array}$} & \multicolumn{2}{|c|}{$\begin{array}{l}\text { Tobit, subject random } \\
\text { effects }\end{array}$} & \multicolumn{2}{|c|}{$\begin{array}{l}\text { Tobit, session random } \\
\text { effects }\end{array}$} \\
\hline & (1) & (2) & (3) & (4) & (5) & (6) \\
\hline Suggested Effort & $\begin{array}{l}0.166^{*} \\
(0.076)\end{array}$ & $\begin{array}{l}0.172 * \\
(0.077)\end{array}$ & $\begin{array}{l}0.305^{*} \\
(0.146)\end{array}$ & $\begin{array}{l}0.313^{*} \\
(0.147)\end{array}$ & $\begin{array}{l}0.298 \\
(0.154)\end{array}$ & $\begin{array}{l}0.306^{*} \\
(0.155)\end{array}$ \\
\hline Fixed wage & $\begin{array}{l}0.004 * * * \\
(0.001)\end{array}$ & $\begin{array}{l}0.004 * * * \\
(0.001)\end{array}$ & $\begin{array}{l}0.005 * \\
(0.002)\end{array}$ & $\begin{array}{l}0.005 * \\
(0.002)\end{array}$ & $\begin{array}{l}0.004 * \\
(0.002)\end{array}$ & $\begin{array}{l}0.004 * \\
(0.002)\end{array}$ \\
\hline $\mathrm{BC}$ & $\begin{array}{l}0.675 \\
(1.526)\end{array}$ & $\begin{array}{l}0.597 \\
(1.530)\end{array}$ & $\begin{array}{l}0.462 \\
(2.853)\end{array}$ & $\begin{array}{l}0.492 \\
(2.859)\end{array}$ & $\begin{array}{l}0.728 \\
(3.103)\end{array}$ & $\begin{array}{l}0.837 \\
(3.110)\end{array}$ \\
\hline $\mathrm{BC} x$ fixed wage & $\begin{array}{l}0.000 \\
(0.001)\end{array}$ & $\begin{array}{l}0.000 \\
(0.001)\end{array}$ & $\begin{array}{l}0.001 \\
(0.003)\end{array}$ & $\begin{array}{l}0.001 \\
(0.003)\end{array}$ & $\begin{array}{l}0.001 \\
(0.003)\end{array}$ & $\begin{array}{l}0.001 \\
(0.003)\end{array}$ \\
\hline $\begin{array}{l}\text { BC } \mathrm{x} \text { announced } \\
\text { bonus }\end{array}$ & $\begin{array}{l}0.005^{* * *} \\
(0.001)\end{array}$ & $\begin{array}{l}0.005^{* * *} \\
(0.001)\end{array}$ & $\begin{array}{l}0.007 * * * \\
(0.001)\end{array}$ & $\begin{array}{l}0.007 * * * \\
(0.001)\end{array}$ & $\begin{array}{l}0.007 * * * \\
(0.002)\end{array}$ & $\begin{array}{l}0.007 * * * \\
(0.002)\end{array}$ \\
\hline IC & $\begin{array}{l}7.192 * * * \\
(1.483)\end{array}$ & $\begin{array}{l}7.190 * * * \\
(1.498)\end{array}$ & $\begin{array}{l}6.784 * \\
(2.858)\end{array}$ & $\begin{array}{l}7.010 * \\
(2.893)\end{array}$ & $\begin{array}{l}8.3131 * * \\
(3.065)\end{array}$ & $\begin{array}{l}8.623 * * \\
(3.093)\end{array}$ \\
\hline IC $x$ fixed wage & $\begin{array}{l}-0.004 * * \\
(0.002)\end{array}$ & $\begin{array}{l}-0.004 * * \\
(0.002)\end{array}$ & $\begin{array}{l}-0.006^{*} \\
(0.003)\end{array}$ & $\begin{array}{l}-0.006 \\
(0.003)\end{array}$ & $\begin{array}{l}-0.006 \\
(0.003)\end{array}$ & $\begin{array}{l}-0.006 \\
(0.003)\end{array}$ \\
\hline IC $x$ share & $\begin{array}{l}8.375 * * \\
(3.027)\end{array}$ & $\begin{array}{l}8.327 * * \\
(3.035)\end{array}$ & $\begin{array}{l}27.180 * * * \\
(6.988)\end{array}$ & $\begin{array}{l}26.800 * * * \\
(7.001)\end{array}$ & $\begin{array}{l}24.700 * * * \\
(7.127)\end{array}$ & $\begin{array}{l}24.270^{* * *} \\
(7.135)\end{array}$ \\
\hline $\begin{array}{l}\text { IC } x \text { Incentive } \\
\text { compatible offer }\end{array}$ & $\begin{array}{l}3.741 * * * \\
(0.976)\end{array}$ & $\begin{array}{l}3.785 * * * \\
(0.978)\end{array}$ & $\begin{array}{l}5.383 * * \\
(2.057)\end{array}$ & $\begin{array}{l}5.480 * * \\
(2.060)\end{array}$ & $\begin{array}{l}5.596 * * \\
(2.116)\end{array}$ & $\begin{array}{l}5.706 * * \\
(2.119)\end{array}$ \\
\hline Game TBI & $\begin{array}{l}-0.913 \\
(0.638)\end{array}$ & $\begin{array}{l}-1.496 \\
(0.807)\end{array}$ & $\begin{array}{l}-2.865^{*} \\
(1.339)\end{array}$ & $\begin{array}{l}-3.186 \\
(1.720)\end{array}$ & $\begin{array}{l}-2.808 \\
(1.482)\end{array}$ & $\begin{array}{l}-2.847 \\
(1.903)\end{array}$ \\
\hline $\begin{array}{l}\text { Exogenous } \\
\text { Contract }\end{array}$ & $\begin{array}{l}-1.055^{*} \\
(0.473)\end{array}$ & $\begin{array}{l}-1.524 * \\
(0.726)\end{array}$ & $\begin{array}{l}-2.264 * \\
(0.952)\end{array}$ & $\begin{array}{l}-2.279 \\
(1.504)\end{array}$ & $\begin{array}{l}-2.121 * \\
(1.052)\end{array}$ & $\begin{array}{l}-1.731 \\
(1.663)\end{array}$ \\
\hline Total round & & $\begin{array}{l}-0.024 \\
(0.083)\end{array}$ & & $\begin{array}{l}-0.090 \\
(0.167)\end{array}$ & & $\begin{array}{l}-0.135 \\
(0.184)\end{array}$ \\
\hline TBI-r round & & $\begin{array}{l}-0.142 \\
(0.162)\end{array}$ & & $\begin{array}{l}-0.008 \\
(0.356)\end{array}$ & & $\begin{array}{l}0.118 \\
(0.394)\end{array}$ \\
\hline Constant & $\begin{array}{l}1.044 \\
(1.365)\end{array}$ & $\begin{array}{l}1.593 \\
(1.442)\end{array}$ & $\begin{array}{l}-2.447 \\
(2.726)\end{array}$ & $\begin{array}{l}2.145 \\
(2.910)\end{array}$ & $\begin{array}{l}-2.835 \\
(2.842)\end{array}$ & $\begin{array}{l}-2.791 \\
(3.054)\end{array}$ \\
\hline AIC & 4047.46 & 4055.22 & 2500.0 & 2503.7 & 2548.1 & 2551.6 \\
\hline BIC & 4114.48 & 4131.11 & 2562.9 & 2575.4 & 2606.4 & 2618.9 \\
\hline Log Likelihood & -2008.73 & -2010.61 & -1236.0 & -1235.8 & -1261.0 & -1260.8 \\
\hline
\end{tabular}

Notes: Columns 1 and 2 report coefficients (robust standard errors in parentheses) of hierarchical linear regressions, clustered by sessions and by subjects. To control for data censoring, columns 3/4 and 5/6 contain the results of Tobit regressions, with random effects on subjects and on session level, respectively. Number of Observations: 656. BC and IC are dummies for the bonus and the incentive contract, respectively. ***, **, and * indicate statistical significance at $0.1 \%, 1 \%$ and $5 \%$ level. 
Table 3: Average total revenue by game and contract type

\begin{tabular}{llll}
\hline \hline & $\begin{array}{l}\text { Trust } \\
\text { Contract }\end{array}$ & $\begin{array}{l}\text { Bonus } \\
\text { Contract }\end{array}$ & $\begin{array}{l}\text { Incentive } \\
\text { Contract }\end{array}$ \\
\hline TC-ex & 738 & - & - \\
BC-ex & - & 1302 & - \\
IC-ex & - & - & 2238 \\
TBI & 200 & 1420 & 2389 \\
TBI-r & 813 & 1690 & 2476 \\
\hline \hline
\end{tabular}

Table 4: Share of incompatible incentive contracts by experimental game types

\begin{tabular}{llll}
\hline \hline & $\begin{array}{l}\text { Number of } \\
\text { Observations }\end{array}$ & $\begin{array}{l}\text { Offer more } \\
\text { than } 0.27\end{array}$ & $\begin{array}{l}\text { Offer more } \\
\text { than } 0.27: \%\end{array}$ \\
\hline IC-ex & 72 & 53 & $74 \%$ \\
TBI & 54 & 45 & $83 \%$ \\
TBI-r & 323 & 253 & $78 \%$ \\
\hline \hline
\end{tabular}

Notes: IC-ex denotes an exogenously determined one shot incentive contract. TBI and TBI-r represent contract choice situations in a one shot and repeated game, respectively.

Table 5: Distribution of profits resulting from incentive contracts

\begin{tabular}{llll}
\hline \hline & & $\begin{array}{l}\text { Average } \\
\text { Profit }\end{array}$ & $\begin{array}{l}\text { Relative } \\
\text { Share }\end{array}$ \\
\hline Theoretical & Principal & 5190 & $60 \%$ \\
Prediction & Agent & 3390 & $40 \%$ \\
& Difference & & $21 \%$ \\
\hline \multirow{2}{*}{ Results IC-ex } & Principal & 4206 & $53 \%$ \\
& Agent & 3741 & $47 \%$ \\
& Difference & & $6 \%$ \\
\hline \multirow{2}{*}{ Results TBI } & Principal & 4269 & $53 \%$ \\
& Agent & 3806 & $47 \%$ \\
& Difference & & $6 \%$ \\
\hline \multirow{2}{*}{ Results TBI-r } & Principal & 4359 & $54 \%$ \\
& Agent & 3786 & $46 \%$ \\
& Difference & & $7 \%$ \\
\hline \hline
\end{tabular}

Notes: IC-ex denotes an exogenously determined one shot incentive contract. TBI and TBI-r represent contract choice situations in a one shot and repeated game, respectively. 
Table 6: Average and standard deviation of profits across contracts

\begin{tabular}{llllllll}
\hline \hline & & \multicolumn{2}{c}{ Trust Contract } & \multicolumn{2}{c}{ Bonus Contract } & \multicolumn{2}{c}{ Incentive Contract } \\
& & Av. Profit & SD & Av. Profit & SD & Av. Profit & SD \\
\hline \multirow{2}{*}{ exogenously } & Principal & $3058(46 \%)$ & 720 & $3657(51 \%)$ & 981 & $4206(53 \%)$ & 757 \\
determined & Agent & $3618(54 \%)$ & 500 & $3505(49 \%)$ & 533 & $3741(47 \%)$ & 467 \\
& Total & 6675 & 887 & 7162 & 1086 & 7947 & 862 \\
\hline \multirow{2}{*}{ TBI } & Principal & $2700(44 \%)$ & 173 & $3582(48 \%)$ & 1205 & $4269(53 \%)$ & 577 \\
& Agent & $3496(56 \%)$ & 3 & $3663(52 \%)$ & 542 & $3806(47 \%)$ & 410 \\
& Total & 6196 & 170 & 7245 & 1190 & 8075 & 730 \\
\hline \multirow{2}{*}{ TBI-r } & Principal & $2875(42 \%)$ & 1076 & $3733(49 \%)$ & 988 & $4359(54 \%)$ & 651 \\
& Agent & $3849(58 \%)$ & 668 & $3755(51 \%)$ & 660 & $3786(46 \%)$ & 428 \\
& Total & 6725 & 995 & 7489 & 1136 & 8145 & 768 \\
\hline \hline
\end{tabular}

Notes: TBI and TBI-r represent contract choice situations in a one shot and repeated game, respectively. 